\title{
Proline Based Chiral Ionic Liquids for Enantioselective Michael Reaction
}

\author{
Kaoru Nobuoka, ${ }^{1}$ Satoshi Kitaoka, ${ }^{2}$ Tsutomu Kojima, ${ }^{1}$ \\ Yuuki Kawano, ${ }^{1}$ Kazuya Hirano, ${ }^{1}$ Masakazu Tange, ${ }^{1}$ Shunsuke Obata, ${ }^{1}$ \\ Yuki Yamamoto, ${ }^{1}$ Thomas Harran, ${ }^{1}$ and Yuich Ishikawa ${ }^{1}$ \\ ${ }^{1}$ Department of Applied Chemistry, Faculty of Engineering, Oita University, 700 Dannoharu, Oita 870-1192, Japan \\ ${ }^{2}$ Department of Biotechnology and Chemistry, Faculty of Engineering, Kinki University, 1 Takaya Umenobe, \\ Higashihiroshima 739-2116, Japan
}

Correspondence should be addressed to Kaoru Nobuoka; nobuokak@oita-u.ac.jp

Received 29 August 2014; Revised 9 November 2014; Accepted 9 November 2014; Published 20 November 2014

Academic Editor: Kazuaki Ishihara

Copyright (c) 2014 Kaoru Nobuoka et al. This is an open access article distributed under the Creative Commons Attribution License, which permits unrestricted use, distribution, and reproduction in any medium, provided the original work is properly cited.

Chiral ionic liquids, starting from (S)-proline, have been prepared and evaluated the ability of a chiral catalyst. In Michael reaction of trans- $\beta$-nitrostyrene and cyclohexanone, all the reactions were carried out under homogeneous conditions without any solvent except for excess cyclohexanone. The chiral ionic liquid catalyst with the positive charge delocalized bulky pyrrolidinium cation shows excellent yields (up to 92\%), diastereoselectivities (syn/anti $=96 / 4$ ), and enantioselectivities (up to 95\% ee) and could be reused at least three times without any loss of its catalytic activity. Such results demonstrated a promising new approach for green and economic chiral synthesis by using the chiral ionic liquids as a chiral catalyst and a chiral medium.

\section{Introduction}

Ionic liquids have been widely used in organic syntheses as catalysts or as reaction media because they are useful and have environmentally benign chemical and physical properties [1-3]. The high designability of ionic liquids is their most attractive and unique property. Also a vast number of possible anion-cation combinations and the introduction of various functional groups onto the structure of ionic liquids produce diverse so-called task-specific ionic liquids for special purposes $[4,5]$. Among many kinds of task-specific ionic liquids, chiral ionic liquids have gained considerable attention not only for chiral synthesis [6] and chiral extraction [7] but also for stationary phases in chiral chromatography $[8,9]$ and chiral NMR shift reagent [10].

There are several strategies to gain access to chiral ionic liquids. One is the racemic ionic liquids synthesis and its subsequent chiral separation of two enantiomers by means of the chiral column chromatography [11] or by chiral cocrystallization [12]. In either case, the chiral separation from the racemic ionic liquids is complicated task because optimising the chiral separation conditions is quite a difficult and the chiral separation also requires an enormous amount of labour and is costly. Another useful methodology is the enantioselective chiral ionic liquids synthesis that produces the pure enantiomer from the achiral precursor using chiral reagents or chiral catalysts. However the chiral catalysts are often expensive and cannot be applied to all kinds of chiral ionic liquids. In addition, the more economic and simpler method are required for the large-scale synthesis of the chiral ionic liquids than ever because the chiral ionic liquids are expected to use as not only the chiral catalyst but also the chiral medium. Therefore, we adopted a different approach, known as the chiral pool synthesis, which uses chiral starting material and maintaining the chirality [13].

Tan et al. reported that the highly polar phosphine oxide moiety of the chiral Michael catalyst interacts with the nitro group of Michael acceptor via dipole interactions mediated by water to produce high yield and enantio- and diastereoselectivity [14]. Similarly, the cationic moiety of the chiral ionic liquid catalysts can interact with the nitro group of Michael acceptor via electrostatic interaction. There have been various 


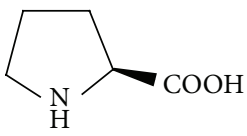

(S)-Proline

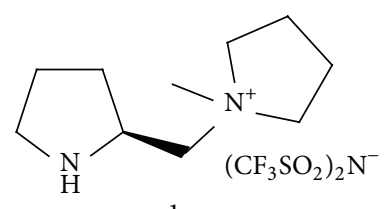

$1 \mathbf{a}$
Figure 1: (S)-Proline and chiral ionic liquid 1a.

reports about the (S)-proline derivative catalysts [15] including chiral ionic liquids catalysts [16-18]. Dąbrowski et al. reported the chiral ionic liquid with pyrrolidine-imidazolium combined cation [16] and the application as an asymmetric catalyst for the asymmetric Michael reaction. However, the Michael adducts were obtained in moderate yield (up to 65\%) while the selectivities were high. In the chiral ionic liquid with pyrrolidine-imidazolium combined cation, the delocalization of the positive charge on the aromatic imidazolium cation does not form a strong electrostatic interaction between the nitro group and the cation, and such a situation seems to affect the yield of Michael adducts.

Therefore, we have recently reported the synthesis of chiral ionic liquids 1 (Figure 1) based on (S)-proline which is a natural chiral amino acid and pyrrolidinium cation moieties [17]. Chiral amino acids are useful precursors of chiral ionic liquids and various natural amino acids mortified ionic liquids were reported [19, 20]. Pyrrolidinium cation is one of the cyclic ammonium cations, and its positive charge was localized on the $\mathrm{N}^{+}$atom unlike the aromatic cations. In order to establish a close interaction with the nitro group, bis(trifluoromethanesulfonyl)imide, which can weaken the cation-anion interaction of ionic liquids, is adopted as an anion of ionic liquids [21]. Vasiloiu et al. reported the application of the chiral ionic liquid $\mathbf{1}$ and its derivatives as an organocatalyst for aldol reaction; however, the aldol products were obtained in moderate yields and selectivities (up to $80 \%$ ee) [18].

In this paper, we examine the preparation and their physical properties of chiral ionic liquids 1 in detail and suitability as enantioselective catalysts for Michael reaction. The close interaction between chiral catalysts and substrates plays a key role in asymmetric synthesis. Unlike a solid catalyst, chiral ionic liquid catalysts can form a homogeneous mixture with substrates in the absence of solvent and thus this situation enables effective interaction between the catalysts and the substrates. Furthermore, the steric hindrance in the transition-state also affects the selectivities of Michael adducts. The bulky pyrrolidinium cation of chiral ionic liquids 1 can also play a critical role in selectivities. In addition, we investigated the reusability and the recyclability of the ionic liquids catalyst for the reactions.

\section{Materials and Methods}

2.1. Materials. All reagents and solvents except for HPLC solvents were of reagent grade and were purchased from commercial sources (Sigma-Aldrich, Nacalai Tesque, 3M, Wako and Kishida) and used without further purification. All the ILs were dried in vacuo (under $0.1 \mathrm{mbar}$ ) at $60^{\circ} \mathrm{C}$ for 3 days prior to use. TLC analysis was performed on $0.25 \mathrm{~mm}$ Silica gel Merck $60 \mathrm{~F}_{254}$ plates. NMR spectra were recorded on a Bruker RX300 NMR and a Bruker AV400 NMR $400 \mathrm{MHz}$ spectrometer. Chemical shifts ( $\delta \mathrm{ppm})$ in $\mathrm{CDCl}_{3}$ and DMSO$d_{6}$ were reported downfield from TMS $(0 \mathrm{ppm})$ for ${ }^{1} \mathrm{H}$ NMR.

2.1.1. (S)-1-[(1-tert-Butoxycarbonyl-2-pyrrolidinyl)methyl]-1-methylpyrrolidinium Tosylate (3) (Route A). p-Toluenesulfonyl chloride $(4.6 \mathrm{~g}, 24 \mathrm{mmol})$ was added to a solution of (S)Boc-prolinol $2(2.9 \mathrm{~g}, 15 \mathrm{mmol})$ in pyridine $(25 \mathrm{~mL})$ at $0^{\circ} \mathrm{C}$, and the mixture was then stirred at room temperature overnight. The reaction mixture was diluted with ethyl acetate $(90 \mathrm{~mL})$ and washed five times with cold $1 \mathrm{M}$ hydrochloric acid $(50 \mathrm{~mL})$, two times with sat. $\mathrm{NaHCO}_{3}$ aq $(40 \mathrm{~mL})$, and two times with brine $(25 \mathrm{~mL})$. The ethyl acetate layer was dried over anhydrous sodium sulphate, and the solvent was removed under reduced pressure. $\mathrm{N}$-methylpyrrolidine $(10 \mathrm{~mL}, 95 \mathrm{mmol})$ was added to a portion of the residual colorless liquid (1.5 g, $4.2 \mathrm{mmol})$, and the reaction mixture was refluxed with stirring 3 days. After removal of excess $N$ methylpyrrolidine under reduced pressure, the residue was diluted with water $(10 \mathrm{~mL})$ and washed with ethyl acetate $(10 \mathrm{~mL})$. A spatula tip of activated carbon was added to the aqueous phase and stirred overnight. The activated carbon was removed by filtration, and the solvent was removed under reduced pressure. The residue was further dried in vacuo (under $0.1 \mathrm{mbar}$ ) at $60^{\circ} \mathrm{C}$ for $24 \mathrm{~h}$, which gave a crude brownish solid (yield: $1.4 \mathrm{~g}) .{ }^{1} \mathrm{H}$ NMR $(300 \mathrm{MHz}$; $\left.\mathrm{CDCl}_{3}, \mathrm{Me}_{4} \mathrm{Si}\right) \delta=7.67(d, J=8.4 \mathrm{~Hz}, 2 \mathrm{H}, m$-phenyl $)$, $7.14(d, J=7.2 \mathrm{~Hz}, 2 \mathrm{H}, o$-phenyl), $4.49(\mathrm{t}, J=7.0 \mathrm{~Hz}, 1 \mathrm{H}$, pyrrolidine- $\mathrm{C}(2) \mathrm{H}), 4.17\left(\mathrm{~m}, 1 \mathrm{H}, \mathrm{N}^{+}-\mathrm{CH}\right.$-pyrrolidine), 3.88 $\left(\mathrm{m}, 3 \mathrm{H}, \mathrm{N}^{+}-\mathrm{CH}\right.$-pyrrolidine and pyrrolidinium- $\left.\mathrm{C}(2) \mathrm{H}_{2}\right)$, $3.60\left(\mathrm{~m}, 2 \mathrm{H}\right.$, pyrrolidinium- $\left.\mathrm{C}(5) \mathrm{H}_{2}\right), 3.30\left(\mathrm{~m}, 5 \mathrm{H}, \mathrm{N}^{+}-\mathrm{CH}_{3}\right.$ and pyrrolidine- $\left.\mathrm{C}(5) \mathrm{H}_{2}\right), 2.33\left(\mathrm{~s}, 3 \mathrm{H}\right.$, phenyl- $\left.\mathrm{CH}_{3}\right), 2.23-$ $1.84\left(\mathrm{~m}, 8 \mathrm{H}\right.$, pyrrolidinium- $\mathrm{C}(3) \mathrm{H}_{2}$, pyrrolidinium- $\mathrm{C}(4) \mathrm{H}_{2}$, pyrrolidine- $\mathrm{C}(3) \mathrm{H}_{2}$ and pyrrolidine- $\left.\mathrm{C}(4) \mathrm{H}_{2}\right)$.

\subsection{2. (S)-1-Methyl-1-[(2-pyrrolidinyl)methyl]pyrrolidinium} Bis(trifluoromethanesulfonyl)imide (1a) (Route A). $85 \mathrm{wt} \%$ phosphoric acid was dropwised to a solution of $3(1.0 \mathrm{~g}$, $2.3 \mathrm{mmol}$ ) in THF ( $1 \mathrm{~mL})$, and the solution was stirred for four hours at room temperature. The reaction mixture was diluted with water $(5 \mathrm{~mL})$ and $50 \%$ sodium hydroxide solution was added until the solution is at $\mathrm{pH} 8$. The solution was washed four times with dichloromethane $(10 \mathrm{~mL})$, and lithium bis(trifluoromethanesulfonyl) imide $(0.66 \mathrm{~g}, 2.3 \mathrm{mmol})$ was then added to the aqueous layer. After overnight stirring at room temperature, the solution was extracted three times with dichloromethane $(10 \mathrm{~mL})$ and the dichloromethane layer was dried over anhydrous sodium sulphate. The solvent was removed under reduced pressure which gave a brownish liquid (yield: $0.51 \mathrm{~g}, 1.1 \mathrm{mmol}, 50 \%$ (crude)).

2.1.3. (S)-1-[(1-tert-Butoxycarbonyl-2-pyrrolidinyl)methyl]pyrrolidine (4) (Route B). p-Toluenesulfonyl chloride (4.6 g, $24 \mathrm{mmol}$ ) was added to a solution of (S)-Boc-prolinol 2 
$(2.9 \mathrm{~g}, 15 \mathrm{mmol})$ in pyridine $(25 \mathrm{~mL})$ at $0^{\circ} \mathrm{C}$, and the mixture was then stirred at room temperature overnight. The reaction mixture was diluted with ethyl acetate $(90 \mathrm{~mL})$ and washed five times with cold $1 \mathrm{M}$ hydrochloric acid $(50 \mathrm{~mL})$, two times with sat. $\mathrm{NaHCO}_{3} \mathrm{aq}(40 \mathrm{~mL})$, and two times with brine $(25 \mathrm{~mL})$. The ethyl acetate layer was dried over anhydrous sodium sulphate, and the solvent was removed under reduced pressure which gave a colorless liquid. Pyrrolidine $(3 \mathrm{~mL}, 36 \mathrm{mmol})$ was added to a portion of the residual colorless liquid $(1.5 \mathrm{~g}, 4.2 \mathrm{mmol})$, and the reaction mixture was refluxed with stirring overnight. After removal of excess $N$-methylpyrrolidine under reduced pressure, the residue was diluted with chloroform $(10 \mathrm{~mL})$ and washed ten times with water $(10 \mathrm{~mL})$. The chloroform layer was dried over anhydrous sodium sulphate, and the solvent was removed under reduced pressure which gave a yellowish liquid (yield: $0.90 \mathrm{~g}, 3.5 \mathrm{mmol} \mathrm{83 \% ).}{ }^{1} \mathrm{H} \mathrm{NMR}$ $\left(300 \mathrm{MHz} ; \mathrm{CDCl}_{3}, \mathrm{Me}_{4} \mathrm{Si}\right) \delta=3.93$ (br, $1 \mathrm{H}$, pyrrolidine$\mathrm{C}(2) \mathrm{H}), 3.63-3.39\left(\mathrm{~m}, 1 \mathrm{H}, \mathrm{N}^{+}\right.$-CH-pyrrolidine), 3.32 (br, $2 \mathrm{H}$, pyrrolidine- $\left.\mathrm{C}(5) \mathrm{H}_{2}\right), 2.61-2.46\left(\mathrm{~m}, 5 \mathrm{H}, \mathrm{N}^{+}-\mathrm{CH}\right.$-pyrrolidine, pyrrolidinium- $\mathrm{C}(2) \mathrm{H}_{2}$ and pyrrolidinium- $\left.\mathrm{C}(5) \mathrm{H}_{2}\right), 2.00-$ $1.73\left(\mathrm{~m}, 8 \mathrm{H}\right.$, pyrrolidinium-C $(3) \mathrm{H}_{2}$, pyrrolidinium- $\mathrm{C}(4) \mathrm{H}_{2}$, pyrrolidine- $\mathrm{C}(3) \mathrm{H}_{2}$ and pyrrolidine- $\left.\mathrm{C}(4) \mathrm{H}_{2}\right), 1.47(\mathrm{~s}, 9 \mathrm{H}$, Boc).

2.1.4. (S)-1-[(1-tert-Butoxycarbonyl-2-pyrrolidinyl)methyl]-1methylpyrrolidinium Iodide (5a) (Route B). Methyl iodide $(0.26 \mathrm{~mL}, 4.2 \mathrm{mmol})$ was added to $4(0.75 \mathrm{~g}, 2.9 \mathrm{mmol})$, and the reaction mixture was refluxed with stirring for four hours. After removal of excess methyl iodide under reduced pressure, the residue was diluted with water $(10 \mathrm{~mL})$ and washed three times with ethyl acetate $(25 \mathrm{~mL})$. A spatula tip of activated carbon was added to the aqueous phase and stirred overnight. The activated carbon was removed by filtration, and the solvent was removed under reduced pressure. The residue was further dried in vacuo (under $0.1 \mathrm{mbar}$ ) at $60^{\circ} \mathrm{C}$ for $24 \mathrm{~h}$, which gave a yellowish solid (yield: $0.85 \mathrm{~g}, 2.1 \mathrm{mmol} 72 \%$ ). ${ }^{1} \mathrm{H}$ NMR (300 $\mathrm{MHz} ; \mathrm{CDCl}_{3}$, $\left.\mathrm{Me}_{4} \mathrm{Si}\right) \delta=4.28(\mathrm{br}, 1 \mathrm{H}$, pyrrolidine-C $(2) \mathrm{H}), 4.10-4.01(\mathrm{~m}, 3 \mathrm{H}$, $\mathrm{N}^{+}$-CH-pyrrolidine and pyrrolidine- $\left.\mathrm{C}(5) \mathrm{H}_{2}\right), 3.92-3.86(\mathrm{~m}$, $1 \mathrm{H}, \mathrm{N}^{+}-\mathrm{CH}$-pyrrolidine $), 3.80-3.74(\mathrm{~m}, 1 \mathrm{H}$, pyrrolidinium$\mathrm{C}(2) \mathrm{H}), 3.65-3.60$ ( $\mathrm{m}, 1 \mathrm{H}$, pyrrolidinium-C $(2) \mathrm{H}), 3.49-$ $3.37\left(\mathrm{~m}, 5 \mathrm{H}, \mathrm{N}^{+}-\mathrm{CH}_{3}\right.$ and pyrrolidinium- $\left.\mathrm{C}(5) \mathrm{H}_{2}\right), 2.36-$ $2.03\left(\mathrm{~m}, 7 \mathrm{H}\right.$, pyrrolidinium- $\mathrm{C}(3) \mathrm{H}$, pyrrolidinium- $\mathrm{C}(4) \mathrm{H}_{2}$, pyrrolidine- $\mathrm{C}(3) \mathrm{H}_{2}$ and pyrrolidine- $\left.\mathrm{C}(4) \mathrm{H}_{2}\right), 1.98-1.92(\mathrm{~m}$, $1 \mathrm{H}$, pyrrolidinium-C $(3) \mathrm{H}) 1.45$ (s, 9H, Boc).

2.1.5. (S)-1-[(1-tert-Butoxycarbonyl-2-pyrrolidinyl)methyl]-1ethylpyrrolidinium Bromide (5b) (Route B). 5b was prepared from 4 and ethyl bromide in the same procedure as that of $\mathbf{5 a}$ (yield: 68\%). ${ }^{1} \mathrm{H}$ NMR (300 MHz; $\left.\mathrm{CDCl}_{3}, \mathrm{Me}_{4} \mathrm{Si}\right) \delta=4.28-$ $4.08\left(\mathrm{~m}, 3 \mathrm{H}\right.$, pyrrolidine- $\mathrm{C}(2) \mathrm{H}$ and pyrrolidine- $\left.\mathrm{C}(5) \mathrm{H}_{2}\right)$, 3.94-3.65 (m, 5H, N $\mathrm{N}^{+}-\mathrm{CH}_{2}$-pyrrolidine, pyrrolidinium$\mathrm{C}(2) \mathrm{H}_{2}$ and pyrrolidinium-C $\left.(5) \mathrm{H}\right), 3.49-3.42(\mathrm{~m}, 3 \mathrm{H}$, pyrrolidinium-C(5)H and $\left.\mathrm{N}^{+}-\mathrm{CH}_{2} \mathrm{CH}_{3}\right), 2.37-1.91(\mathrm{~m}, 8 \mathrm{H}$, pyrrolidine- $\mathrm{C}(3) \mathrm{H}_{2}$, pyrrolidine- $\mathrm{C}(4) \mathrm{H}_{2}$, pyrrolidinium$\mathrm{C}(3) \mathrm{H}_{2}$ and pyrrolidinium- $\left.\mathrm{C}(4) \mathrm{H}_{2}\right), 1.45-1.40(\mathrm{~m}, 12 \mathrm{H}$, $\mathrm{N}^{+}-\mathrm{CH}_{2}-\mathrm{CH}_{3}$ and $\left.\mathrm{Boc}\right)$.
2.1.6. (S)-1-Methyl-1-[(2-pyrrolidinyl)methyl]pyrrolidinium Bis(trifluoromethanesulfonyl)imide (1a) (Route B). $85 \mathrm{wt} \%$ phosphoric acid was dropwised to a solution of $5 \mathbf{a}(0.4 \mathrm{~g}$, $1.0 \mathrm{mmol})$ in THF $(0.5 \mathrm{~mL})$, and the solution was stirred for four hours at room temperature. The reaction mixture was diluted with water and $50 \%$ of sodium hydroxide solution was added until the solution is at $\mathrm{pH}$. Water $(20 \mathrm{~mL})$ was added to the solution and the solution was washed three times with dichloromethane $(20 \mathrm{~mL})$. Lithium bis(trifluoromethanesulfonyl)imide $(0.29 \mathrm{~g}, 1.0 \mathrm{mmol})$ was added to the aqueous layer and the solution was stirred overnight at room temperature. The solution was extracted three times with dichloromethane $(10 \mathrm{~mL})$ and the dichloromethane layer was dried over anhydrous sodium sulphate. The solvent was removed under reduced pressure which gave a yellowish liquid (yield: $0.32 \mathrm{~g}$, $0.71 \mathrm{mmol}, 71 \%$ ). $[\mathrm{M}]_{589}^{25}=+47.3$ (c 5 in methanol). ${ }^{1} \mathrm{H}$ NMR $\left(300 \mathrm{MHz} ; \mathrm{CDCl}_{3}, \mathrm{Me}_{4} \mathrm{Si}\right) \delta=3.57-3.77(5 \mathrm{H}, \mathrm{m}$, pyrrolidine- $\mathrm{C}(2) \mathrm{H}$, pyrrolidinium- $\mathrm{C}(2) \mathrm{H}_{2}$, pyrrolidinium$\left.\mathrm{C}(5) \mathrm{H}_{2}\right), 3.31-3.36\left(1 \mathrm{H}, \mathrm{m}, \mathrm{N}^{+}-\mathrm{CH}\right.$-pyrrolidine $), 3.11-3.19$ (4H, m, $\mathrm{N}^{+}-\mathrm{Me}$ and $\mathrm{N}^{+}-\mathrm{CH}$-pyrrolidine), 2.82-2.99 $(1 \mathrm{H}, \mathrm{m}$, pyrrolidine- $\mathrm{C}(5) \mathrm{H}), 2.75-2.80(1 \mathrm{H}, \mathrm{m}$, pyrrolidine- $\mathrm{C}(5) \mathrm{H})$, $2.24\left(4 \mathrm{H}\right.$, br, pyrrolidinium- $\mathrm{C}(3) \mathrm{H}_{2}$ and pyrrolidinium$\left.\mathrm{C}(4) \mathrm{H}_{2}\right), 2.05-2.13(1 \mathrm{H}, \mathrm{m}$, pyrrolidine- $\mathrm{C}(3) \mathrm{H}), 1.55-1.95$ $\left(2 \mathrm{H}, \mathrm{m}\right.$, pyrrolidine- $\left.\mathrm{C}(4) \mathrm{H}_{2}\right), 1.34-1.38(1 \mathrm{H}, \mathrm{m}$, pyrrolidine$\mathrm{C}(3) \mathrm{H}) .{ }^{13} \mathrm{C} \mathrm{NMR}\left(100.40 \mathrm{MHz} ; \mathrm{CDCl}_{3}, \mathrm{Me}_{4} \mathrm{Si}\right)$ 20.9, 21.6, 25.7, 31.0, 47.1, 48.8, 54.1, 65.3, 65.2, $121.4\left(\mathrm{t}, J_{\mathrm{CF}}=320 \mathrm{~Hz}\right)$. Anal. Calcd for $\mathrm{C}_{12} \mathrm{H}_{21} \mathrm{~F}_{6} \mathrm{~N}_{3} \mathrm{O}_{4} \mathrm{~S}_{2}$ : C, 32.07; H, 4.71; N, 9.35. Found: C, 31.81; H, 4.75; N, 9.49\%.

2.1.7. Preparation of (S)-1-Ethyl-1-[(2-pyrrolidinyl)methyl]pyrrolidinium Bis(trifluoromethanesulfonyl)imide (1b) (Route B). $\mathbf{1 b}$ was prepared from $\mathbf{5 b}$ in the same procedure as that of la (yield: $72 \%$ ). [M $]_{589}^{25}=+35.8$ (c 5 in methanol). ${ }^{1} \mathrm{H}$ NMR (300 MHz; $\left.\mathrm{CDCl}_{3}, \mathrm{Me}_{4} \mathrm{Si}\right) \delta=4.00-3.91(\mathrm{~m}$, $1 \mathrm{H}$, pyrrolidine- $\mathrm{C}(2) \mathrm{H}), 3.64-3.45\left(\mathrm{~m}, 6 \mathrm{H}, \mathrm{N}^{+}-\mathrm{CH}_{2} \mathrm{CH}_{3}\right.$, pyrrolidinium- $\mathrm{C}(2) \mathrm{H}_{2}$ and pyrrolidinium- $\left.\mathrm{C}(5) \mathrm{H}_{2}\right)$, 3.142.98 (m, 3H, pyrrolidine- $\mathrm{C}(5) \mathrm{H}$ and $\mathrm{N}^{+}-\mathrm{CH}_{2}$-pyrrolidine), 2.81-2.75 (m, $1 \mathrm{H}$, pyrrolidine- $\mathrm{C}(5) \mathrm{H}), 2.20-2.05(\mathrm{~m}, 5 \mathrm{H}$, pyrrolidine- $\mathrm{C}(3) \mathrm{H}$, pyrrolidinium- $\mathrm{C}(3) \mathrm{H}_{2}$, pyrrolidinium$\left.\mathrm{C}(4) \mathrm{H}_{2}\right), 1.81-1.61\left(\mathrm{~m}, 2 \mathrm{H}\right.$, pyrrolidine- $\left.\mathrm{C}(4) \mathrm{H}_{2}\right), 1.41-1.31(\mathrm{~m}$, $4 \mathrm{H}$, pyrrolidine- $\mathrm{C}(3) \mathrm{H}$ and $\left.\mathrm{N}^{+}-\mathrm{CH}_{2}-\mathrm{CH}_{3}\right)$.

2.2. Viscosities. The viscosities were measured with a DVII + Pro Programmable Cone/Plate (CPE-51) Viscometer (BROOKFIELD) at $22^{\circ} \mathrm{C}$ via an external temperature controller. Each sample comprised $0.5 \mathrm{~mL}$.

2.3. Molar Optical Rotation. The molar optical rotations were measured at $589 \mathrm{~nm}$ and $25^{\circ} \mathrm{C}$ in methanol solutions with a P1010 Polarimeter (JASCO).

2.4. Determination of Glass Transition Temperatures (Tg). The glass transition temperatures were determined by using a DSC6100 (SII) under a $\mathrm{N}_{2}$ atmosphere using a heating rate and cooling rate of $2^{\circ} \mathrm{C} \mathrm{min}^{-1}$.

2.5. General Method of Asymmetric Michael Reaction in Chiral Ionic Liquids (1a). A mixture of chiral ionic liquids 1a 


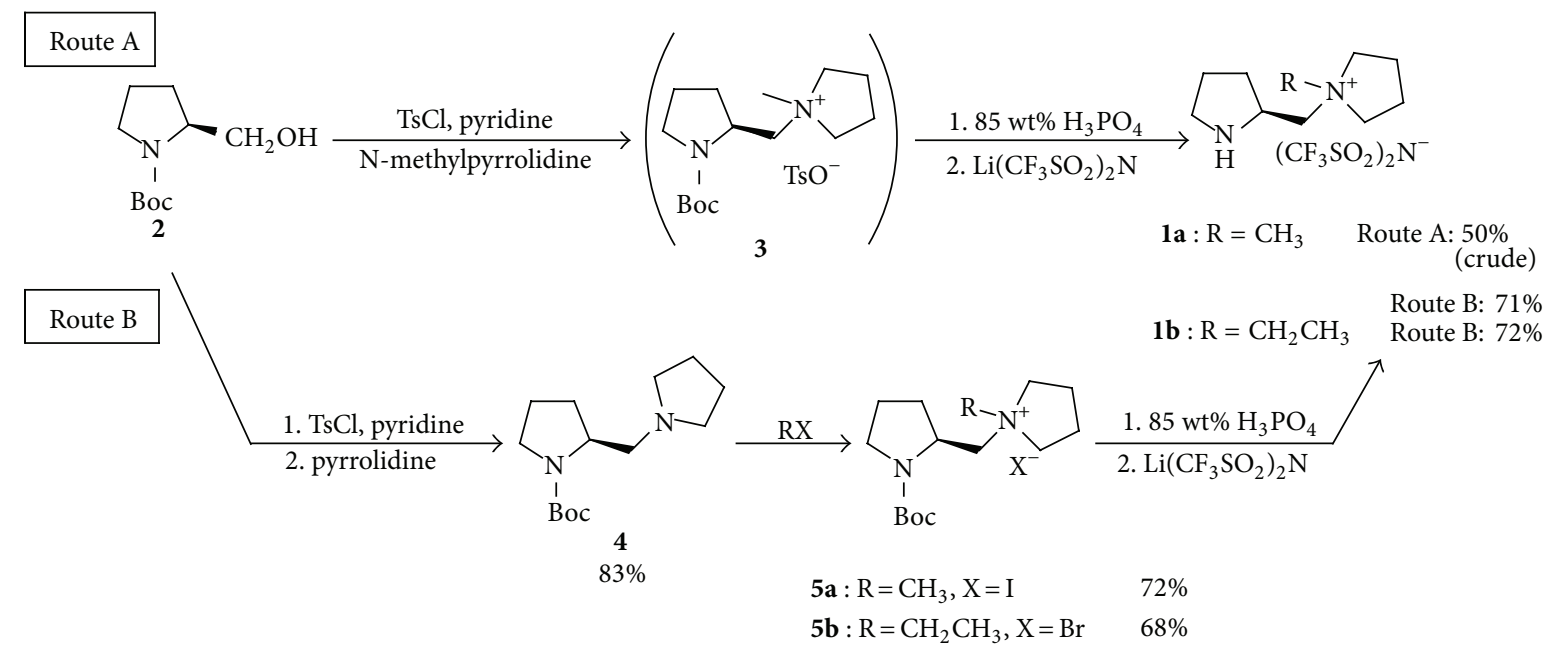

SCHEME 1: Synthesis of (S)-proline based chiral ionic liquids $\mathbf{1 .}$

(28 mg, $63 \mu \mathrm{mol})$, cyclohexanone $(0.52 \mathrm{~mL}, \quad 5.0 \mathrm{mmol})$, trans- $\beta$-nitrostyrene (37 mg, $0.25 \mathrm{mmol})$, and TFA $(0.93 \mu \mathrm{L}$, $0.013 \mathrm{mmol}$ ) was stirred 48 hours at room temperature $\left(25^{\circ} \mathrm{C}\right)$ without any solvent except for excess cyclohexanone. After their reactions, hexane $(5 \mathrm{~mL})$ was added to the reaction mixture; thus the yellowish catalyst la could be separated. The upper hexane layer was removed and the remaining catalyst la layer was then extracted again with hexane $(5 \mathrm{~mL})$ and two times with diethyl ether $(5 \mathrm{~mL})$. The combined organic layers were evaporated and the remaining crude residual oil was purified by means of flash column chromatography on silica gel using hexane/ethyl acetate $(4: 1)$ as an eluent to in order to produce pure Michael adducts. ${ }^{1} \mathrm{H}$ NMR $\left(300 \mathrm{MHz} ; \mathrm{CDCl}_{3}, \mathrm{Me}_{4} \mathrm{Si}\right) \delta=7.34-7.15(\mathrm{~m}, 5 \mathrm{H}$, phenyl), 4.98-4.92 (m, $\left.1 \mathrm{H}, \mathrm{CH}-\mathrm{NO}_{2}\right), 4.67-4.60(\mathrm{~m}, 1 \mathrm{H}$, CH-NO ${ }_{2}$ ), 4.05-3.95 (m, 1H, CH-Phenyl, anti), 3.80-3.72 (m, 1H, CH-Phenyl, syn), 2.70-2.60 (m, 1H, 2-CH), 2.51-2.32 (m, 2H, 6- $\left.\mathrm{CH}_{2}\right), 2.18-2.06(\mathrm{~m}, 1 \mathrm{H}, 3-\mathrm{CH}), 1.88-1.50(\mathrm{~m}, 4 \mathrm{H}$, 3-CH, 4-CH, 5- $\mathrm{CH}_{2}$ ), 1.29-1.17 (m, 1H, 4-CH). HPLC (Daicel CHIRALPAK AD-H, n-hexane/2-propanol = 90/10, flow rate $0.5 \mathrm{~mL} \mathrm{~min}^{-1}, 220 \mathrm{~nm}$ ); $\mathrm{tR}=19.5$ (minor), 23.4 (major).

2.6. Reuse of Chiral Ionic Liquids (1a) in Asymmetric Michael Reaction. After the reactions, hexane $(5 \mathrm{~mL})$ was added to the reaction mixture, and the yellowish ionic liquid catalyst la phase containing TFA was separated. After washing with hexane and diethyl ether, it was confirmed using ${ }^{1} \mathrm{H}$ NMR that la phase does not contain any impurities except for TFA. Cyclohexanone and trans- $\beta$-nitrostyrene were added to the recovered la and TFA solution, and the reaction was repeated.

\section{Results and Discussion}

3.1. Preparation of Chiral Ionic Liquids (1). The chiral ionic liquids were synthesized starting from (S)-proline which is a natural abundant chiral amino acid. As aforementioned, (S)proline and its derivatives are useful catalysts for enaminemediated reactions $[15,25]$. Pyrrolidinium cation is a bulky cyclic five-member ring ammonium cation, and its positive charge is localized on the $\mathrm{N}^{+}$atom in contrast to the aromatic cations. The localized positive charge of chiral ionic liquids 1 can effectively interact with the nitro group of Michael acceptor. In addition to the bulky cyclic five-member pyrrolidinium ring, the quaternary ammonium nitrogen of pyrrolidinium is close to an asymmetric point at $\mathrm{Cl}$ of pyrrolidine ring. Compared to aromatic imidazolium and pyridinium cations, the chiral ionic liquids 1 have a greater steric effect around the asymmetric point, which is most likely to produce high catalytic activities and selectivities.

(S)-Boc-prolinol 2 was easily prepared according to literature via (S)-Boc-proline in two steps [21]. After the tosyl group which is a good leaving group was introduced into the (S)-Boc-prolinol 2, introduction of another pyrrolidine ring and quaternization was accomplished. First, we tried to synthesize compound la with $N$-methylpyrrolidine conveniently (Scheme 1, Route A). This one-step quaternization required a rigorous reaction condition and produced the corresponding tosylate salt 3 in relatively high crude yield (76\%) with a small amount of impurities. The impurities could not be removed even in the next deprotection and the subsequent anion exchange steps.

Then, we attempted to synthesize ionic liquids 1 under a mild reaction condition (Route $\mathrm{B}$ ). The tosyl group was replaced to pyrrolidine ring, and subsequent quaternization led to pure compound 5 in relative high yields. Since the compound 5 was decomposed in trifluoroacetic acid (TFA) solution, deprotection of N-Boc was accomplished by treatment of $85 \mathrm{wt} \%$ phosphoric acid solution. Anion exchange reactions with lithium bis(trifluoromethanesulfonyl)imide afforded the water immiscible room temperature ionic liquids 1.

3.2. Physical Properties of Chiral Ionic Liquids (1). The thermal properties of $\mathbf{1 a}$ and $\mathbf{1 b}$ were determined by differential scanning calorimetry (DSC). Both $\mathbf{1 a}$ and $\mathbf{1 b}$ have low glass transition temperatures $\left(T_{g}\right)$ of $-73.6^{\circ} \mathrm{C}(\mathbf{1 a})$ and 
TABLE 1: Enantioselective Michael reaction of trans- $\beta$-nitrostyrene with cyclohexanone in the presence of $\mathbf{1 a}^{\mathrm{a}}$.

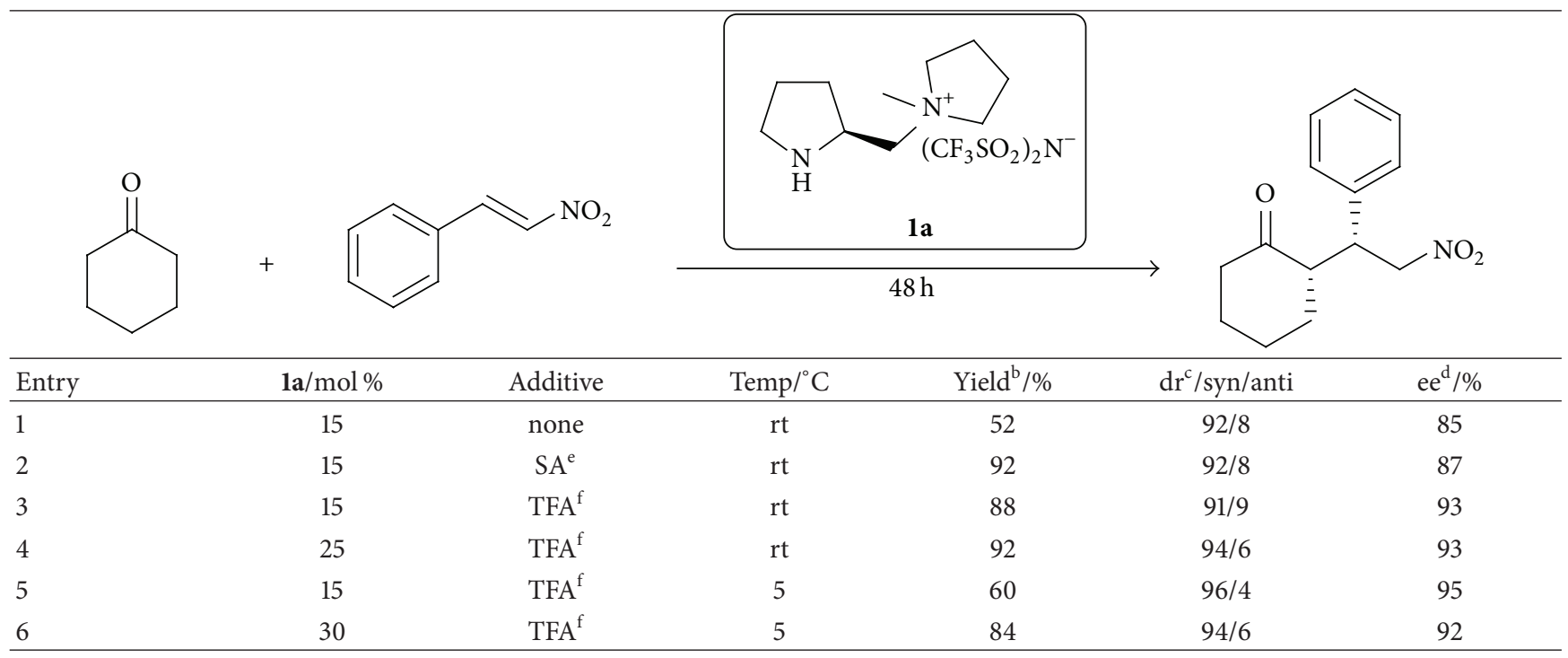

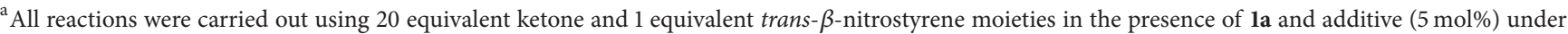
neat conditions at room temperature for $48 \mathrm{~h}$. ${ }^{\mathrm{b}}$ Isolated yield. ${ }^{\mathrm{c}}$ Determined by ${ }^{1} \mathrm{H}$ NMR spectroscopy. ${ }^{\mathrm{d}}$ Determined by chiral HPLC analysis (CHIRALPAK AD-H). ${ }^{\mathrm{e}}$ Salicylic acid. ${ }^{\mathrm{f}}$ Trifluoroacetic acid.

$-72.5^{\circ} \mathrm{C}(\mathbf{l b})$. The two $T_{g}$ values show that the difference in alkyl chain length between methyl and ethyl does not affect their thermal properties. The optical activity was determined in the methanol solution. The molar optical

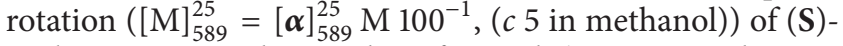
proline is -98.0 , whereas that of $\mathbf{1 a}$ and $\mathbf{1 b}$ is +47.3 and +35.8 , respectively. The multistep syntheses reverse the direction of the optical rotation from levorotary to dextrorotatory. The viscosity of $\mathbf{1 a}$ is $123 \mathrm{cP}$ at $25^{\circ} \mathrm{C}$. The viscosity of $\mathbf{1 a}$ is slightly higher than that of $N$-butyl- $N$-methylpyrrolidinium bis(trifluoromethanesulfonyl)imide $\left(89 \mathrm{cP}\right.$ at $\left.25^{\circ} \mathrm{C}\right)$, which is composed of similar pyrrolidinium cation, due to the bulky cationic structure of 1a. The chiral ionic liquids with pyrrolidine-imidazolium combined cation were used in the Michael reaction by diluting with dichloromethane [16]. By contrast, the viscosity of $\mathbf{l a}$ is fluid enough to be used as a reaction medium, and the close interaction with substrates is expected.

\subsection{Ability of (1a) as a Chiral Catalyst for Michael Reaction.} We evaluated the ability of $\mathbf{1 a}$ as a chiral catalyst in an enamine-based enantioselective Michael reaction of trans- $\beta$ nitrostyrene with cyclohexanone. The reactions were carried out in the presence of 1a as a catalyst for 48 hours at room temperature without any solvent except for excess cyclohexanone. After their reactions, hexane $(5 \mathrm{~mL})$ was added to the reaction mixture; thus the yellowish catalyst la could be separated. The upper hexane layer was removed and the remaining catalyst la layer was then extracted again with hexane $(5 \mathrm{~mL})$ and with diethyl ether $(2 \times 5 \mathrm{~mL})$. The combined organic layers were evaporated and the remaining crude residual oil was purified by means of flash column chromatography on silica gel using hexane/ethyl acetate $(4: 1)$ as an eluent to in order to produce pure Michael adducts.
The results of this study are summarized in Table 1 . In the presence of $15 \mathrm{~mol} \%$ la, the Michael adducts formed with relatively high diastereoselectivity $(\operatorname{syn} /$ anti $=92 / 8)$ and enantioselectivity ( $85 \%$ ee), although the yield was moderate (entry 1). When (S)-proline was used as a catalyst, the Michael adducts were obtained in very low enantioselectivity while the yield and diastereoselectivity were high (80\% yield, syn/anti $=98 / 2,61 \%$ ee, data not shown in Table 1 ). This result suggests that ionic liquids $\mathbf{1 a}$ is an effective catalyst for enantioselective Michael reaction. Then, $5 \mathrm{~mol} \%$ of Brønsted acid was added to the reaction mixture in order to improve yields by accelerating the enamine formation and protonation of the zwitterionic intermediate [26-28]. The employment of salicylic acid (SA) as an additive led to an improvement in yield ( $92 \%$, entry 2$)$. In case of TFA, not only the yield but also the enantioselectivity was improved ( $88 \%$ yield, $93 \%$ ee, entry 3). Mase et al. reported the asymmetric Michael reaction with pyrrolidine-pyrrolidine combined diamine catalyst with TFA [29]. Although the yield and stereoselectivity were same level, the enantioselectivity can be improved from $89 \%$ ee to $93 \%$ ee by employing the chiral ionic liquids 1a. In the case of the chiral ionic liquids with pyrrolidine-imidazolium combined cation, benzoic acid was employed as an additive. However, the yield was moderate (up to 65\%) and selectivities were not improved [16]. These results provide evidence of the importance of the electrostatic interaction with a Michael acceptor, the positive charge delocalization, and the steric effect of pyrrolidinium cation.

While high diastereo- and enantioselectivities were ensured at the low temperature $\left(5^{\circ} \mathrm{C}\right)$, the yield decreased owing to decrease a reaction rate according as the temperature declines (entry 5). With increases in catalyst ratio from $15 \mathrm{~mol} \%$ to $30 \mathrm{~mol} \%$, the yield is improved from $60 \%$ to $80 \%$ (entry 6). As a result, high catalyst loading (25 mol\%) at room 
TABLE 2: Reusability of the ionic liquid catalyst la for enantioselective Michael reaction ${ }^{\mathrm{a}}$.

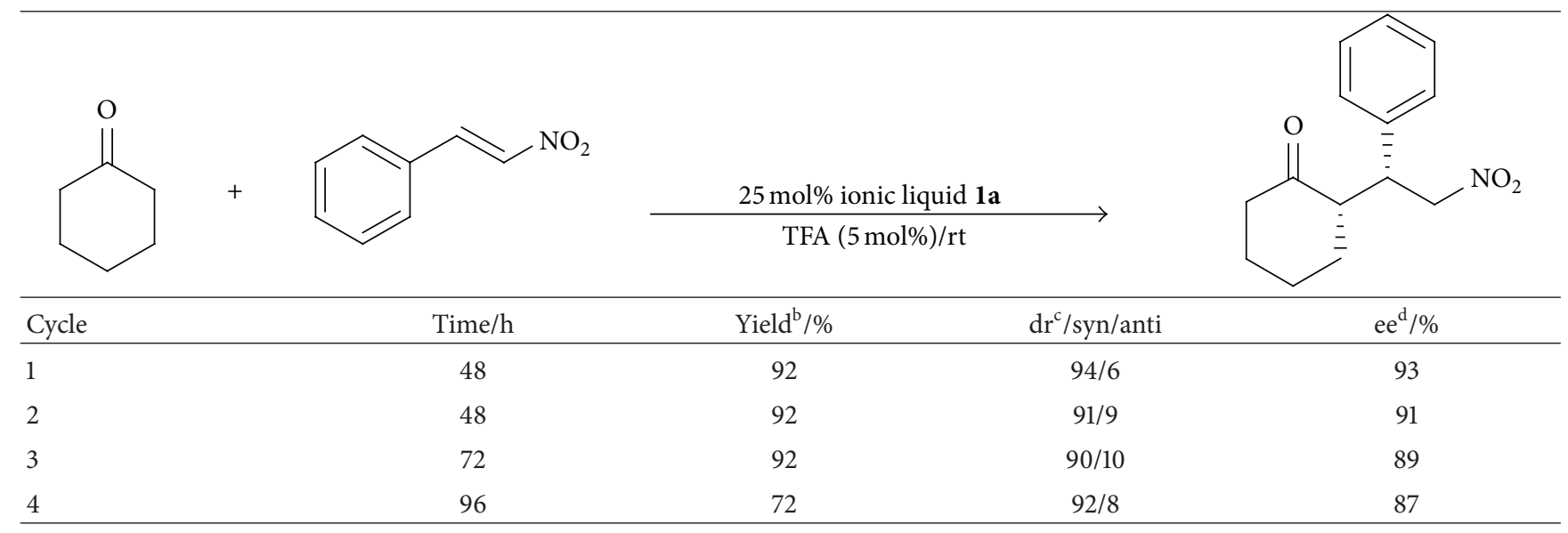

${ }^{a}$ All reactions were carried out using 20 equivalent cyclohexanone and 1 equivalent trans- $\beta$-nitrostyrene in the presence of $1 \mathbf{a}(25 \mathrm{~mol} \%)$ and trifluoroacetic acid (TFA) (5 mol\%) under neat conditions at room temperature. ${ }^{b}$ Isolated yield. ${ }^{c}$ Determined by ${ }^{1} \mathrm{H}$ NMR spectroscopy. ${ }^{\mathrm{d}}$ Determined by chiral HPLC analysis (CHIRALPAK AD-H).

(Transition state $\mathbf{I}$ )

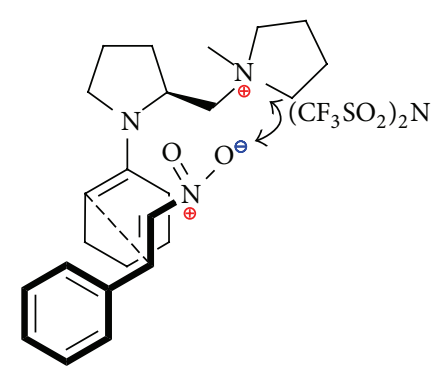

FIgURE 2: Plausible transition state structure for the Michael reaction between cyclohexanone and trans- $\beta$-nitrostyrene using the chiral ionic liquid 1a.

temperature enables one to achieve the best value of yield, diastereoselectivity, and enantioselectivity (entry 4).

On the basis of the stereochemistry and the Houk-List $[25,30]$ and Seebach and Golinski [31] transition state models, two plausible transition state structures for the Michael reaction between cyclohexanone and trans- $\beta$-nitrostyrene using the chiral ionic liquid la can be proposed as shown Figure 2. The pyrrolidinium cation of 1a would electrostatically interact with the nitro oxygen of trans- $\beta$-nitrostyrene in the transition state $\mathbf{I}$. The steric hindrance of pyrrolidinium cation of la could shield the Si face of the enamine double bond in the ketone donor in transition state II. Accordingly, the trans- $\beta$-nitrostyrene as a Michael acceptor would approach the enamine from the Re face in both transition states. Considering that 1a containing pyrrolidinium cation gave the higher enantioselectivity than pyrrolidinepyrrolidine combined diamine catalyst [29], we propose that the electrostatic interaction with pyrrolidinium cation of $\mathbf{1 a}$ and nitro oxygen of trans- $\beta$-nitrostyrene can form the transition state $\mathbf{I}$ and the steric hindrance of pyrrolidinium cation of la can shield the access of the nitro group. Consequently, the double bond of trans- $\beta$-nitrostyrene arranges near the enamine double bond, and the high selectivity is observed.

3.4. Reusability of (1a) for Michael Reaction. Table 2 shows the reusability of $\mathbf{1 a}$ for the Michael reaction. The reaction conditions are the same as those of the entry 4 in Table 1. Ionic liquid catalyst 1a phase containing TFA was easily separated from the reaction mixture and the la phase was reused four times after washing with hexane and diethyl ether. The ${ }^{1} \mathrm{H}$ NMR spectra showed that the reused catalyst la phase containing TFA was pure in each cycle. The diastereo- and enantioselectivity of the reused catalyst remained almost the same after four cycles, though the yields decreased gradually. Although it is difficult to show the recovery rate of catalyst la because of including TFA, the amount of recovered catalyst la phase was visibly reduced slightly. It is possible to surmise that the loss of catalyst $\mathbf{1 a}$ and TFA for extraction and purification steps in each cycle makes the reactions slower. Thus, the reaction time was extended to 72 hours for the three cycles to obtain the same yield as the first and the second cycles. The yield of the fourth cycle fell to $72 \%$, even if the reaction time was extended to 96 hours. Hence, the ionic liquid catalyst la can be reused at least three times without significant loss of activity. Moreover, Xu et al. also reported the reusability of chiral ionic liquid catalyst with pyrrolidine-DABCO combined cation using $[\mathrm{bmim}]\left[\mathrm{BF}_{4}\right]$ as a reaction solvent [32]. In our proposed la reuse system, the reactions were carried out under homogeneous conditions without any reaction solvent except for excess cyclohexanone. The solvent free system enables not only contact interaction with substrates but also enables a simple recycling and reuse operation system to be produced.

3.5. Generality of Ionic Liquid Catalyst (1a). To evaluate the generality of the ionic liquid catalyst 1a, various trans- $\beta$ nitrostyrene derivatives and ketones were examined under 
TABLE 3: Enantioselective Michael reaction of various trans- $\beta$-nitrostyrene derivatives with several ketones and an aldehyde in the presence of $1 a^{\mathrm{a}}$.

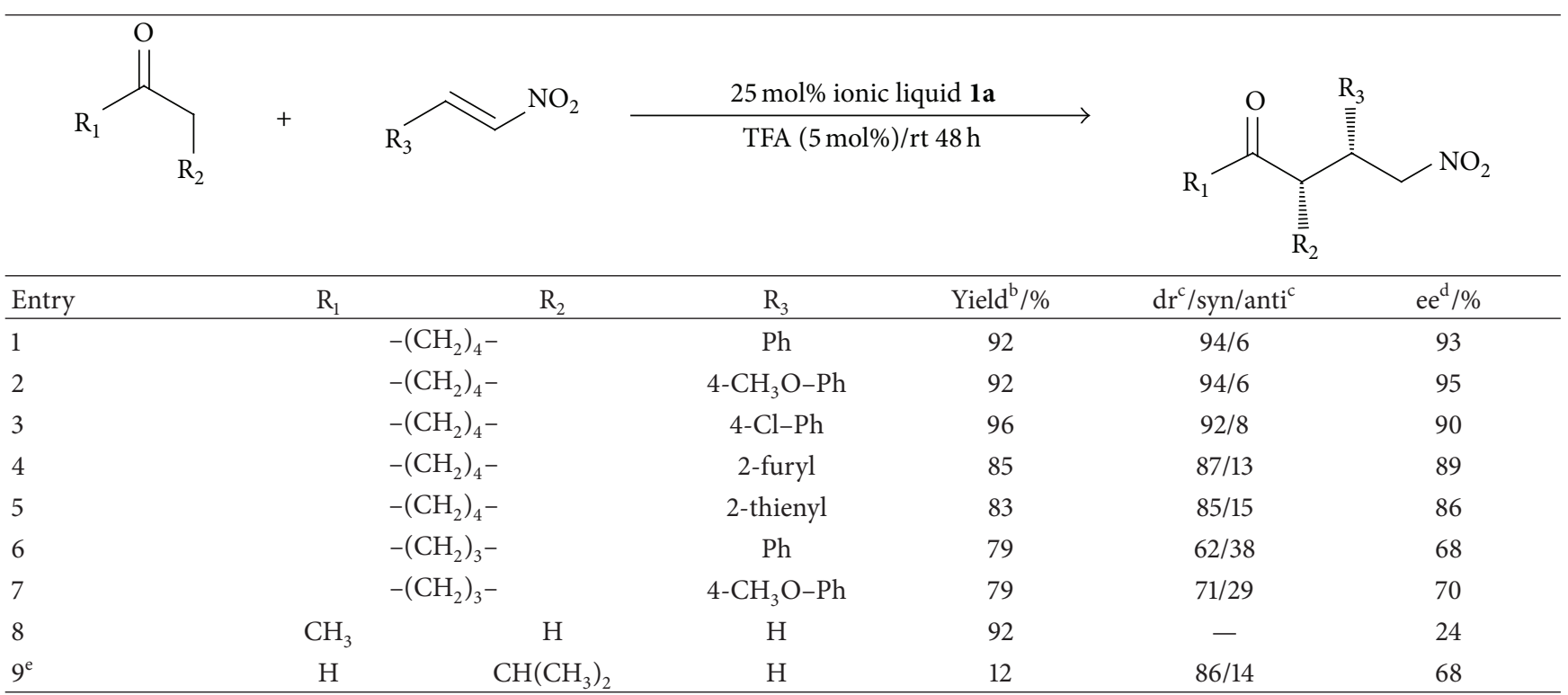

${ }^{a}$ All reactions were carried out using 20 equivalent ketone and 1 equivalent trans- $\beta$-nitrostyrene moieties in the presence of $1 \mathbf{a}(25$ mol\%) and trifluoroacetic acid (TFA) (5 mol\%) under neat conditions at room temperature for $48 \mathrm{~h} .{ }^{b}$ Isolated yield. ${ }^{c}$ Determined by ${ }^{1} \mathrm{H}$ NMR spectroscopy. ${ }^{\mathrm{d}}$ Determined by chiral HPLC analysis (CHIRALPAK AD-H) according to references [22-24]. ${ }^{\mathrm{e}}$ Amount of $\mathbf{l a}$ was $15 \mathrm{~mol} \%$ and reaction time was 7 days.

the same conditions (Table 3). Entry 2 and entry 3 show the influence of electronic (substituent) properties of trans$\beta$-nitrostyrene derivatives on the catalytic ability of $\mathbf{1 a}$. The introduction of the electron donating methoxy group at the paraposition of the phenyl ring shows excellent yield and selectivities (entry 2). In case of the electron-withdrawing chloride group (entry 3), the Michael adducts were obtained with excellent yield and selectivities though both selectivities decreased slightly compared to entry 1 and entry 2 . Thus, the electronic properties of trans- $\beta$-nitrostyrene derivatives do not affect the catalytic ability of $\mathbf{1 a}$.

In case of using trans-2-(2-nitrovinyl) furan and trans2-(2-nitrovinyl) thiophene which are the heteroaryl nitro olefins, the Michael adducts were obtained in high yields and selectivities (entry 4 and entry 5). When cyclopentanone was used as a Michael donor, lower diastereo- and enantioselectivities were observed (syn/anti $=62 / 38,68 \%$ ee, entry 6) in contrast with cyclohexanone (entry 1). The employment of trans-4-methoxy- $\beta$-nitrostyrene as a Michael acceptor led to an improvement in the selectivities ( $70 \%$ ee, entry 7 ). The acyclic ketone (acetone) led to the lowest enantioselectivity ( $24 \%$ ee, entry 8 ). Compared to the bulky cyclohexanone and cyclopentanone with six or fivemembered ring, acetone is a very simple ketone. It is possible to surmise that trans- $\beta$-nitrostyrene as an electrophile could attack the enamine intermediate from both sides because of the absence of the steric hindrance of the enamine intermediate derived from acetone and 1a. As shown in entry 9, isovaleraldehyde also led to the relatively high enantioand diastereoselectivities (syn/anti $=86 / 14,68 \%$ ee) though the yield was low (12\%). The amount of 1a was decreased from $25 \mathrm{~mol} \%$ to $15 \mathrm{~mol} \%$ and the reaction time was extended for 7 days because of the lower solubility of 1a toward the reaction mixture with isovaleraldehyde. In addition to the lower steric hindrance of the aldehyde, the amount of catalyst la has effects on the yield. In order to obtain high yields and selectivities with various substrates, we conducted further improvements of the ionic liquid catalyst structure and the physical properties.

\section{Conclusions}

We have synthesized proline based chiral ionic liquid catalysts with two five-membered unsaturated aza-heterocycles for enantioselective reactions by means of chiral enamine intermediates. The chiral ionic liquids show a liquid state at room temperature with relatively low viscosity, and such properties produce effective homogeneous reaction without any other solvent except for excess cyclohexanone. The ionic liquid catalyst afforded Michael products with high yields and diastereo- and enantioselectivities and thus can be reused at least three times without less selectivity. Such results demonstrated a promising new approach for green and economic chiral synthesis by using the chiral ionic liquids as a chiral catalyst and a chiral medium. Further investigations of other enamine-catalysed enantioselective reactions and optimization of its structure are being conducted in our laboratory for effective chiral derivation on wide substrates.

\section{Conflict of Interests}

The authors declare that there is no conflict of interests regarding the publication of this paper. 


\section{Acknowledgments}

This research was supported by Japan Society for the Promotion of Science, Grant-in-Aid for Young Scientists (B) (21710089, 2009-2010, and 22710103, 2010-2011), by Japan Science and Technology Agency, Research for Promoting Technological Seeds (16-020) and Adaptable and Seamless Technology Transfer Program through Target-Driven R\&D (A-STEP, no. AS242Z02498M), and by Oita University, Venture Business Support Program Project C. Elementary analysis was measured at the Centre of Elementary Analysis, Faculty of Sciences, Kyushu University.

\section{References}

[1] V. I. Pârvulescu and C. Hardacre, "Catalysis in ionic liquids," Chemical Reviews, vol. 107, no. 6, pp. 2615-2665, 2007.

[2] H. Olivier-Bourbigou, L. Magna, and D. Morvan, "Ionic liquids and catalysis: recent progress from knowledge to applications," Applied Catalysis A: General, vol. 373, no. 1-2, pp. 1-56, 2010.

[3] J. P. Hallett and T. Welton, "Room-temperature ionic liquids: Solvents for synthesis and catalysis. 2," Chemical Reviews, vol. 111, no. 5, pp. 3508-3576, 2011.

[4] J. H. Davis Jr., "Task-specific ionic liquids," Chemistry Letters, vol. 33, no. 9, pp. 1072-1077, 2004.

[5] R. Giernoth, “Task-specific ionic liquids," Angewandte Chemie: International Edition, vol. 49, no. 16, pp. 2834-2839, 2010.

[6] J. Ding and D. W. Armstrong, "Chiral ionic liquids: Synthesis and applications," Chirality, vol. 17, no. 5, pp. 281-292, 2005.

[7] F. Tang, Q. Zhang, D. Ren, Z. Nie, Q. Liu, and S. Yao, "Functional amino acid ionic liquids as solvent and selector in chiral extraction," Journal of Chromatography A, vol. 1217, no. 28, pp. 4669-4674, 2010.

[8] J. Ding, T. Welton, and D. W. Armstrong, "Chiral ionic liquids as stationary phases in gas chromatography," Analytical Chemistry, vol. 76, no. 22, pp. 6819-6822, 2004.

[9] C. P. Kapnissi-Christodoulou, I. J. Stavrou, and M. C. Mavroudi, "Chiral ionic liquids in chromatographic and electrophoretic separations," Journal of Chromatography A, vol. 1363, pp. 2-10, 2014.

[10] C. Baudequin, D. Brégeon, J. Levillain, F. Guillen, J.-C. Plaquevent, and A.-C. Gaumont, "Chiral ionic liquids, a renewal for the chemistry of chiral solvents? Design, synthesis and applications for chiral recognition and asymmetric synthesis," Tetrahedron: Asymmetry, vol. 16, no. 24, pp. 3921-3945, 2005.

[11] M. L. Patil, C. V. L. Rao, K. Yonezawa, S. Takizawa, K. Onitsuka, and H. Sasai, "Design and synthesis of novel chiral spiro ionic liquids," Organic Letters, vol. 8, no. 2, pp. 227-230, 2006.

[12] V. Zgonnik, C. Zedde, Y. Génisson, M.-R. Mazières, and J.C. Plaquevent, "Synthesis of chiral ionic liquids by ion crossmetathesis: En route to enantioselective water-ionic liquid extraction (EWILE), an eco-friendly variant of the ELLE process," Chemical Communications, vol. 48, no. 26, pp. 3185-3187, 2012.

[13] P. Wasserscheid, A. Bösmann, and C. Bolm, "Synthesis and properties of ionic liquids derived from the 'chiral pool," Chemical Communications, no. 3, pp. 200-201, 2002.

[14] B. Tan, X. Zeng, Y. Lu, P. J. Chua, and G. Zhong, "Rational design of organocatalyst: highly stereoselective michael addition of cyclic ketones to nitroolefins," Organic Letters, vol. 11, no. 9, pp. 1927-1930, 2009.
[15] S. Mukherjee, J. W. Yang, S. Hoffmann, and B. List, "Asymmetric enamine catalysis," Chemical Reviews, vol. 107, no. 12, pp. 54715569, 2007.

[16] Z. Dą̧rowski, A. Wiśniewska, A. Kulig-Adamiak, J. Kamiński, and J. Cybulski, "Ionic liquids as the catalysts for asymmetric reactions," Polimery, vol. 57, no. 5, pp. 375-381, 2012.

[17] K. Nobuoka, S. Kitaoka, and Y. Ishikawa, "Proline based chiral ionic liquids for chiral synthesis," in Proceedings of the 8th Liquid Matter Conference, Conference Book, pp. P1-P28, 2011.

[18] M. Vasiloiu, D. Rainer, P. Gaertner, C. Reichel, C. Schröder, and K. Bica, "Basic chiral ionic liquids: a novel strategy for acid-free organocatalysis," Catalysis Today, vol. 200, no. 1, pp. 80-86, 2013.

[19] K. Fukumoto, M. Yoshizawa, and H. Ohno, "Room temperature ionic liquids from 20 natural amino acids," Journal of the American Chemical Society, vol. 127, no. 8, pp. 2398-2399, 2005.

[20] H. Ohno and K. Fukumoto, "Amino acid ionic liquids," Accounts of Chemical Research, vol. 40, no. 11, pp. 1122-1129, 2007.

[21] K. Nobuoka, S. Kitaoka, A. Yanagisako, Y. Maki, T. Harran, and Y. Ishikawa, "Stereoselectivity of the Diels-Alder reaction in ionic liquids with cyano moieties: effect of the charge delocalization of anions on the relation of solvent-solvent and solute-solvent interactions," RSC Advances, vol. 3, no. 42, pp. 19632-19638, 2013.

[22] V. K. Singh, "Highly enantioselective water-compatible organocatalyst for Michael reaction of ketones to nitroolefins," Organic Letters, vol. 9, no. 6, pp. 1117-1119, 2007.

[23] A. Lu, P. Gao, Y. Wu, Y. Wang, Z. Zhou, and C. Tang, "Highly enantio- and diastereoselective Michael addition of cyclohexanone to nitroolefins catalyzed by a chiral glucosebased bifunctional secondary amine-thiourea catalyst," Organic and Biomolecular Chemistry, vol. 7, no. 15, pp. 3141-3147, 2009.

[24] J. N. Moorthy and S. Saha, "C3-symmetric prolinefunctionalized organocatalysts: Enantioselective michael addition reactions," European Journal of Organic Chemistry, no. 33, pp. 6359-6365, 2010.

[25] B. List, "Proline-catalyzed asymmetric reactions," Tetrahedron, vol. 58, no. 28, pp. 5573-5590, 2002.

[26] N. Zotova, A. Moran, A. Armstrong, and D. G. Blackmond, "A coherent mechanistic rationale for additive effects and autoinductive behaviour in proline-mediated reactions," Advanced Synthesis \& Catalysis, vol. 351, no. 17, pp. 2765-2769, 2009.

[27] K. Patora-Komisarska, M. Benohoud, H. Ishikawa, D. Seebach, and Y. Hayashi, "Organocatalyzed michael addition of aldehydes to nitro alkenes-generally accepted mechanism revisited and revised," Helvetica Chimica Acta, vol. 94, no. 5, pp. 719-745, 2011.

[28] J. Burés, A. Armstrong, and D. G. Blackmond, "Curtinhammett paradigm for stereocontrol in organocatalysis by diarylprolinol ether catalysts," Journal of the American Chemical Society, vol. 134, no. 15, pp. 6741-6750, 2012.

[29] N. Mase, K. Watanabe, H. Yoda, K. Takabe, F. Tanaka, and C. F. Barbas III, "Organocatalytic direct Michael reaction of ketones and aldehydes with $\beta$-nitrostyrene in brine," Journal of the American Chemical Society, vol. 128, no. 15, pp. 4966-4967, 2006.

[30] S. Bahmanyar, K. N. Houk, H. J. Martin, and B. List, "Quantum mechanical predictions of the stereoselectivities of prolinecatalyzed asymmetric intermolecular aldol reactions," Journal of the American Chemical Society, vol. 125, no. 9, pp. 2475-2479, 2003. 
[31] D. Seebach and J. Golinski, "Synthesis of open-chain $2,3-$ disubstituted 4-nitroketones by diastereoselective Michaeladdition of $(E)$-enamines to $(E)$-nitroolefins. A topological rule for $\mathrm{C}, \mathrm{C}$-bond forming processes between prochiral centres. Preliminary communication," Helvetica Chimica Acta, vol. 64, no. 5, pp. 1413-1423, 1981.

[32] D.-Z. Xu, Y. Liu, S. Shi, and Y. Wang, "Chiral quaternary alkylammonium ionic liquid [Pro-dabco][BF4]: as a recyclable and highly efficient organocatalyst for asymmetric Michael addition reactions," Tetrahedron Asymmetry, vol. 21, no. 20, pp. 2530-2534, 2010. 

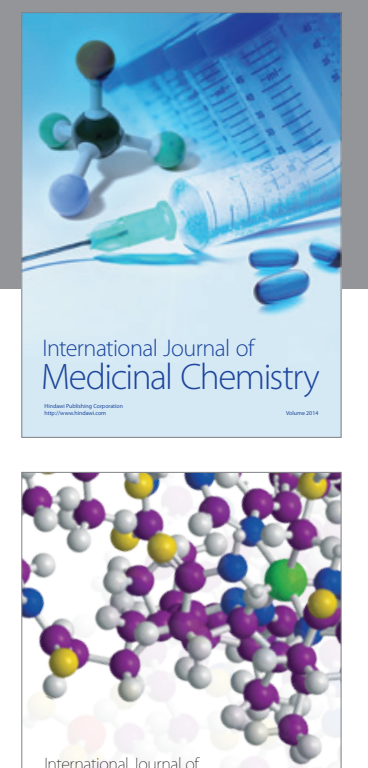

\section{Carbohydrate} Chemistry

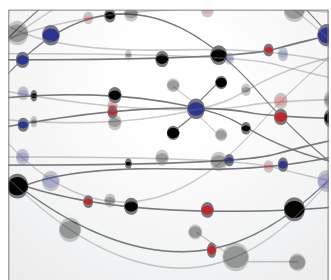

The Scientific World Journal
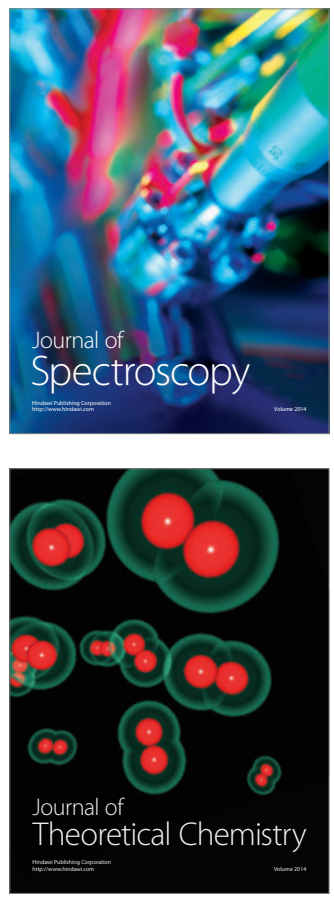
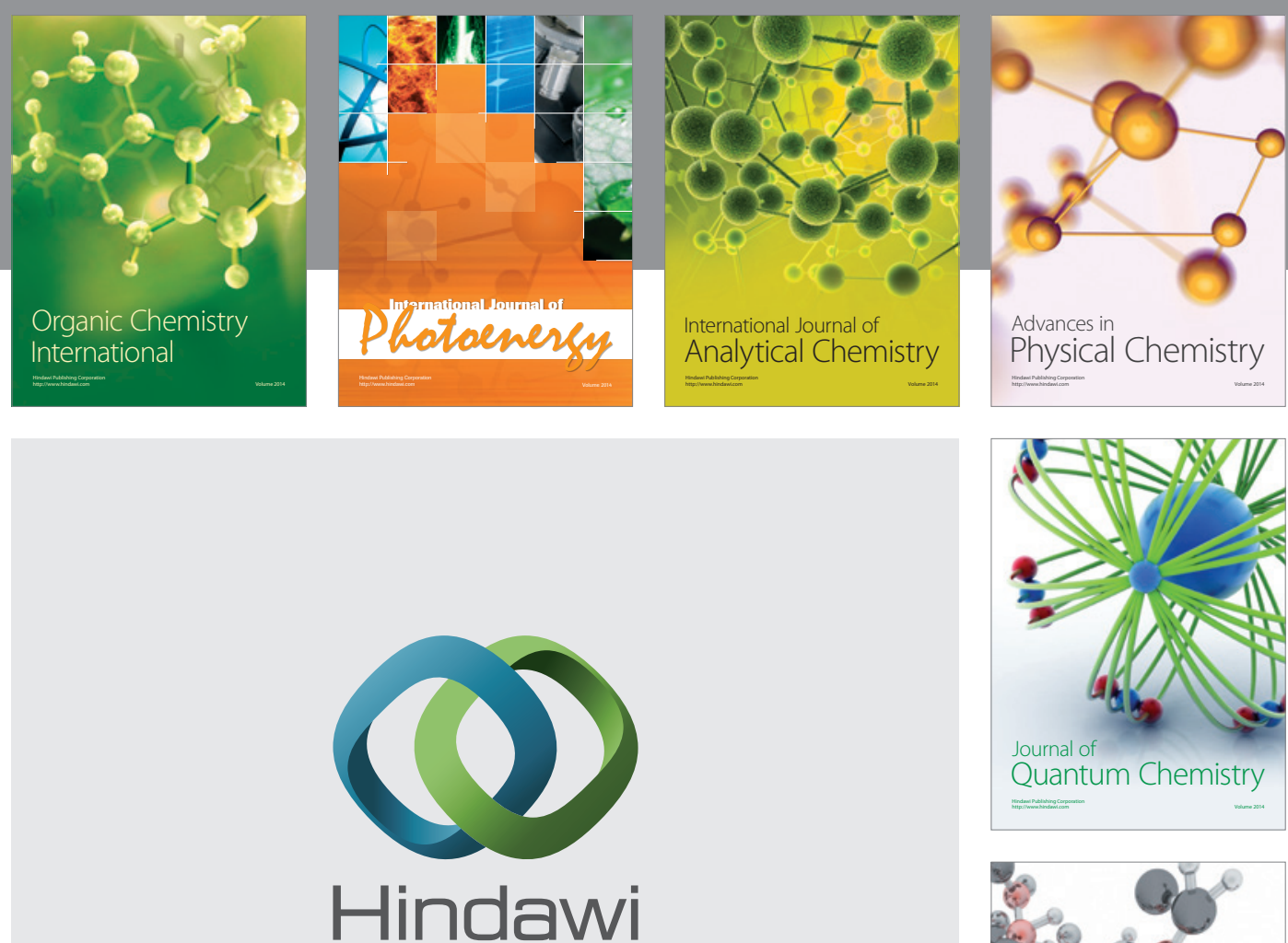

Submit your manuscripts at

http://www.hindawi.com

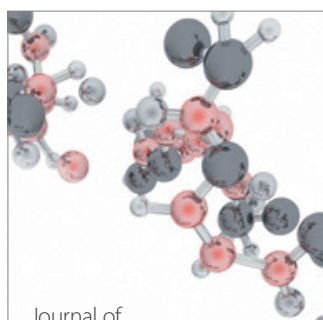

Analytical Methods

in Chemistry

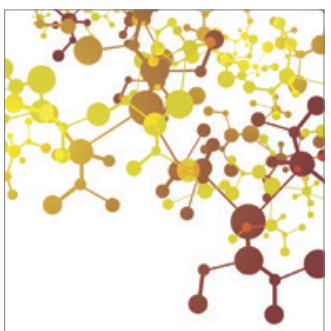

Journal of

Applied Chemistry

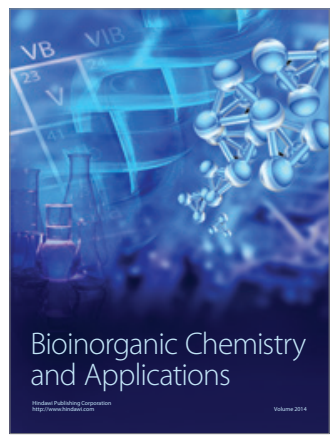

Inorganic Chemistry
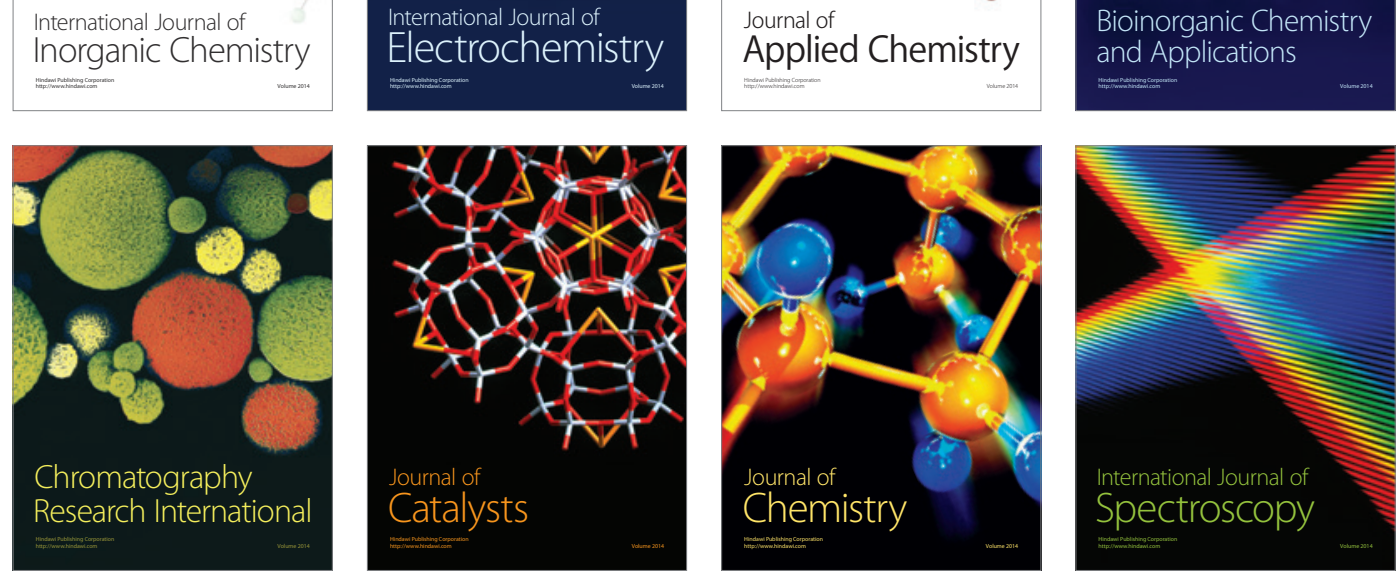